TO:

Director, National Institute for Occupational Safety and Health

FROM: lowa FACE

Case No. 2005IA019

Report Date: 3 July 2008

\title{
SUBJECT: Exit pit worker entangled in horizontal directional drill back reamer
}

\section{SUMMARY}

A 34-year-old man was fatally injured while working in a four-man crew installing a large diameter water line along a rural lowa roadway mid spring of 2005. The crew was using a horizontal directional drilling (HDD) machine to pilot bore and pull back pipe (the product line) underneath a wooded area

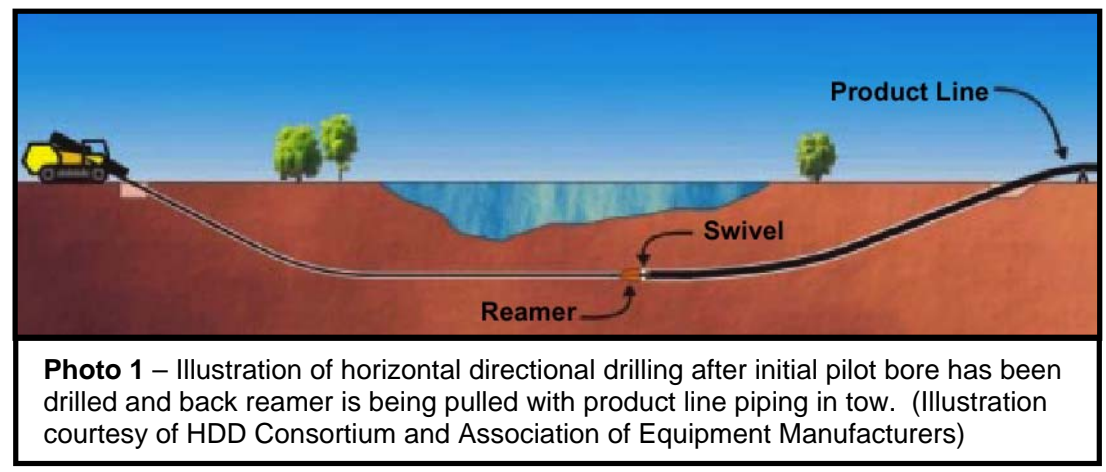
(Photo 1). After completion of the pilot bore, the exit pit worker was alone in the exit pit 600 feet $(183 \mathrm{~m})$ from the drill rig operator. The worker removed the drill bit to attach a back reamer to the end of the drill rod. A pulling head was attached to the pipe and a swivel between the pulling head and the back reamer completed the connection between the HDD machine and the product line pipe. The drill rig operator radioed the exit pit worker asking if he was ready for the reamer to be rotated and for the pullback or back-reaming operation to begin. The exit pit worker responded affirmatively. Soon after engaging power, the operator radioed to learn how the reamer was progressing but there was no response. The operator halted power to the drill line and radioed for help to check on the exit pit worker. The supervisor discovered the victim's body wrapped around the drill line in the area of the pre-cutter just ahead of the back reamer.

\section{RECOMMENDATIONS}

1. Personnel must be positioned a safe distance from the drill line and reamer before the drill line is energized and rotated, and they must never step over rotating drill pipe.

2. When available, horizontal directional drilling units should be equipped with remote lockout. 
3. Two-way radio communication between the entry and exit areas must be maintained at all times and the drill line must not be rotated until all personnel have been notified and acknowledgement has been made by all personnel.

4. Personnel should be trained to safely operate horizontal directional drilling equipment and supervised to ensure that they are following proper safety procedures.

\section{INTRODUCTION}

Mid spring 2005, a 34-year-old construction worker died while installing pipe with a horizontal directional drilling (HDD) machine. The victim had attached the swivel between the pipe and back reamer. The victim reportedly replied affirmatively to the rig operator who then energized the drill pipe. After a few revolutions, the rig operator radioed again. When he received no response, he halted power to the drill line and radioed for help to check on the exit pit worker.

The lowa FACE program learned about this death from the lowa State Medical Examiner's Office and an investigation was initiated. Incident reports from the County Sheriff's Office and the lowa State Medical Examiner were reviewed along with photos from the scene. Other information resources included interviews with the victim's co-workers and supervisor.

\section{INVESTIGATION}

The crew was employed by an excavating company that had a contract with a county in central lowa to provide directional drilling services during water line installation. The victim's job as part of the four-man crew was to track the drilling head from the horizontal directional drilling (HDD) machine and observe its emergence at the exit site. He was also responsible for attaching a reamer to the end of the drill line and for connecting the swivel between the reamer and pulling head on the product line pipe. This pipe was to be slipped into position inside the bore during the back-reaming operation as the reamer was pulled back through the enlarged bore hole.

A co-worker operated the power source for the drill line at the entry pit and the co-workers maintained radio communications although they could not see each other. His other co-worker was operating a bulldozer. The supervisor for the operation was in a pickup truck retrieving a map and planning the next drilling operation. All three were working well away from the victim and none observed the incident as it occurred.

HDD has been increasingly used to lay telecommunications, electric, water, and sewer lines without gross disruptions of the surface topography. A wide range of directional drilling units exist in the marketplace. The smallest rigs are used to lay telecommunications and residential electrical distribution lines and larger rigs are used to install pipelines up to 48 inches $(1.2 \mathrm{~m})$ diameter. The rig used in this incident was a mid-size machine pulling pipe approximately one foot $(0.3 \mathrm{~m})$ in diameter.

The drilling distance is typically less than $700 \mathrm{ft}(215 \mathrm{~m})$ for small rigs, less than $2000 \mathrm{ft}(610 \mathrm{~m})$ for moderately sized rigs, and less than $6000 \mathrm{ft}(1825 \mathrm{~m})$ for large rigs. The workers in this incident were drilling a distance between 1000 and 2000 feet (305 to $610 \mathrm{~m}$ ) underneath a 
wooded area. Medium-sized drilling rigs are capable of producing a torque up to $20,000 \mathrm{lb}-\mathrm{ft}$ $(27,116 \mathrm{~N}-\mathrm{m})$ with a rotational speed of $200 \mathrm{rpm}$.

Horizontal directional drilling begins when the HDD machine extends a rotating drill pipe with a guidable cutting head on the end of it into a small entry pit. It proceeds with the drilling of a pilot bore. The function of the drill pipe or line is to transmit rotational torque from the drill rig to the working cutting head, transport drilling fluids, and pull the pipe into position as it retracts the hole-enlarging back reamer. The drilling pipe enters the ground at an angle until it reaches the desired depth. The rotating drill head then drills through the soil until it is again angled toward the surface.

Once the drill head reaches the surface at the exit area, the drill bit is removed and a reamer is attached. A trench is excavated to help guide the reamer and the piping it will pull back into the pilot bore. The reamer enlarges the pilot bore sufficiently to allow installation of the pipe. The reamer is typically 1.5 times larger than the diameter of the pipe and in some borings a reamer may be used more than one time. The reamer is attached to a swivel which is attached to the pulling head for the pipe. The drill line is rotated and pulled, drawing the pipe back through the bore hole toward the entry pit.

The drill rig operator had radioed the victim asking if he was ready for the reamer to be rotated and for the pullback or back-reaming to begin. The victim reportedly responded affirmatively. Soon after engaging power, the operator radioed the victim to ask how the reamer was progressing, but received no response. The operator halted power to the drill line and radioed others to have them check on the exit pit area worker. The supervisor discovered the victim's body wrapped around the drill rod just ahead of the reamer.

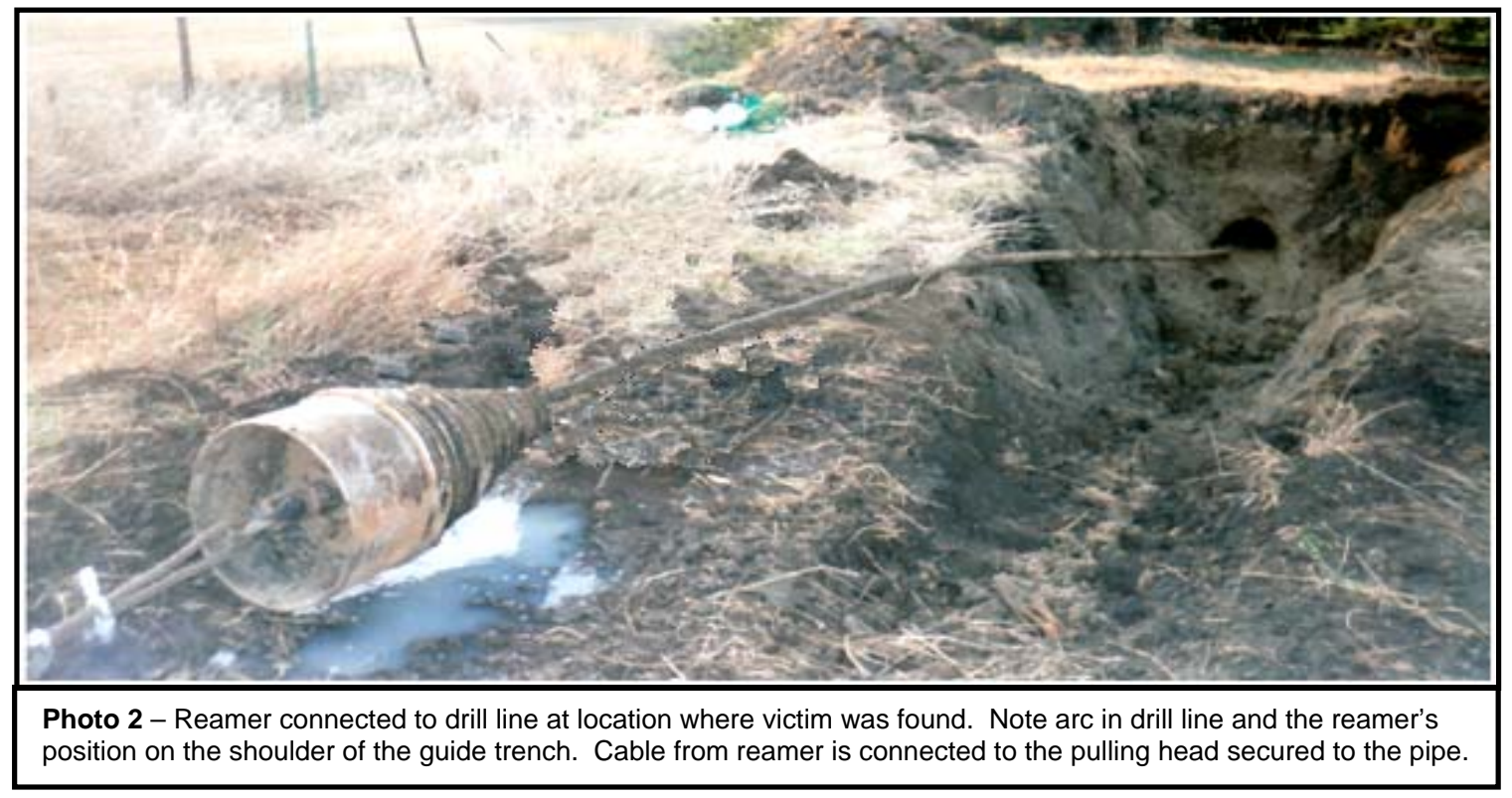

The incident was not witnessed and the exact events leading to the injury are not known. It is likely the victim was standing too close to the line when it began to rotate. The reamer was connected to the drilling pipe and the product line pipe through the swivel, but this connection and the victim were stopped outside the shoulder of the guide trench (Photo 2) with the drilling pipe arced between the reamer and the pilot bore. Based on the position of the drilling pipe, the location of the victim and the reamer, it appears that when the drilling pipe was rotated the 
reamer "walked" or otherwise moved to the side out of the entry trench toward the victim. The victim became entangled in the rotating drilling pipe, pre-cutter, and/or reamer resulting in multiple blunt force injuries.

The victim had no pulse when the supervisor found him. Emergency medical services personnel were called immediately. The incident resulted in multiple blunt force trauma injuries. The victim was pronounced dead at the scene.

\section{CAUSE OF DEATH}

The cause of death according to the medical examiner's report was multiple blunt force injuries.

\section{RECOMMENDATIONS I DISCUSSION}

Recommendation \#1 - Personnel must be positioned a safe distance from the drill line and reamer before the drill line is energized and rotated, and they must never step over rotating drill pipe.

Discussion: Drilling pipe and reamers may rapidly move sideways when rotated. Clothing or body parts of personnel coming in contact with drilling pipe, pre-cutters, and/or reamers may become entangled. The rotational speed and force of the rotating pipe has the potential to cause serious injury or death. Personnel should position themselves a safe distance to the side of the rotating drill line components and behind the reamer so they cannot be contacted by it when it moves. The recommended distance will vary but should not be less than the distance between the reamer and bore opening, and that distance should be communicated to the person controlling the drilling head. Preferably, the back reamer should be pulled into the bore hole opening before rotation is started.

Recommendation \#2 - When available, horizontal directional drilling units should be equipped with remote lockout.

Discussion: Exit side immobilization control of the drill string allows a person remote from the drilling head to disable drill rod movement without being present at the drill head or depending on voice communication with the drill head operator. Such means of remote lockout on machines where this newer technology is applicable, available, properly installed and maintained can supplement reliable communication and adherence to best practices essential for safe operation.

Recommendation \#3 - Two-way radio communication between the entry and exit areas must be maintained at all times and the drill line must not be rotated until all personnel have been notified and acknowledgement has been made by all personnel.

Discussion: Workers often are not in visual contact during horizontal drilling operations so effective communication is vital and it should be established and maintained at all times during drilling operations. Radio protocols, such as confirmation of all messages, as well as visual signals and method of acknowledgement must be established and used. When using radio communication, the operator of the HDD should not start operation until co-workers confirm they are a specified, pre-determined distance from the reamer and drill line. The workers involved in 
this incident were in contact with each other and the failure of the victim to respond via radio caused the rig operator to halt the drilling operation. Radio communications with other workers at this jobsite also allowed the rig operator to quickly contact them for help and reduce the time for first responders to reach the victim.

Recommendation \#4 - Personnel should be trained to safely operate horizontal directional drilling equipment and supervised to ensure that they are following proper safety procedures.

Discussion: The level of safety training that the workers involved in this incident had received is unknown. The victim's position was too close to the reamer and drill line when it was engaged. The importance of maintaining a safe distance must be understood and compliance diligently enforced. The victim was not being directly supervised in this incident, a practice that if done periodically or whenever back reaming operations begin would help ensure proper safety procedures are being followed.

\section{REFERENCES}

AEM (formerly EMI). 2000. Safety manual for operators - Directional drilling tracking equipment. Association of Equipment Manufacturers, Milwaukee, WI.

AEM. 1977 Revised 11/91. Safety manual for operators and mechanics - Trenchers with backhoe, burial plow, and horizontal boring attachments. Association of Equipment Manufacturers, Milwaukee, WI.

Bennett D, et al. 2001. Horizontal directional drilling good practice guidelines. Horizontal Directional Drilling Consortium.

SAE J2305. 2006 (proposed draft). Hazard reduction for horizontal earthboring machines. SAE International. Milwaukee, WI.

Wayne T. Sanderson, PhD, ClH Associate Professor and Director Great Plains Center for Agricultural Health Institute for Rural \& Environmental Health University of lowa - Iowa City, Iowa
Murray D. Madsen, MBA

Chief Trauma Investigator, IA FACE

Associate Director, GPCAH Institute for Rural \& Environmental Health University of lowa - lowa City, lowa 


\section{Fatality Assessment and Control Evaluation FACE}

Fatality Assessment and Control Evaluation, FACE, is a program of the National Institute for Occupational Safety and Health (NIOSH), which is part of the Centers for Disease Control and Prevention of the U.S. Department of Health and Human Services. Nationally, the FACE program identifies traumatic deaths at work, conducts in-depth studies of select work deaths, makes recommendations for prevention, and publishes reports and alerts. The goal is to prevent occupational fatalities across the nation.

The NIOSH head office in Morgantown, West Virginia, carries out an intramural FACE case surveillance and evaluation program and also funds state-based programs in several cooperating states. In lowa, The University of lowa through its Injury Prevention Research Center works in conjunction with the lowa Department of Public Health and its Office of the State Medical Examiner to conduct the lowa FACE program.

Nationally, $\mathrm{NIOSH}$ combines its internal information with that from cooperating states to provide information in a variety of forms which is disseminated widely among the industries involved. $\mathrm{NIOSH}$ publications are available on the web at http://www.cdc.gov/NIOSH/FACE/ and from the NIOSH (1-800-CDC-INFO (1-800-232-4636) or email cdcinfo@cdc.gov).

Iowa FACE also publishes its case studies, issues precautionary messages, and prepares articles for trade and professional publications. In addition to postings on the national NIOSH website, this information is often posted on the lowa FACE website at http://www.publichealth.uiowa.edu/FACE/. Copies of FACE case studies and other publications are also available by contacting lowa FACE directly.

The lowa FACE team includes the following specialists from the University of lowa: Craig Zwerling, MD, PhD, MPH, Principal Investigator; John Lundell, MA, Co-Investigator; Murray Madsen, MBA, Chief Trauma Investigator; and Co-Investigator/specialists Risto Rautiainen, $\mathrm{PhD}$, and Wayne Sanderson, $\mathrm{PhD}, \mathrm{ClH}$. Additional expertise is provided from the lowa Department of Public Health, including Rita Gergely, Principal Investigator, and John Kraemer, PA, from the Office of the State Medical Examiner.

For additional information regarding this report or the lowa FACE Program contact:

lowa FACE

The University of lowa

100 Oakdale Campus, \#203 IREH

lowa City, IA 52242-5000

Toll free within lowa: 800-513-0998

Phone: (319) 335-4481

Fax: (319) 335-4290

Internet: http://www.public-health.uiowa.edu/FACE

E-mail: murray-madsen@uiowa.edu 